\title{
O espaço da mídia na escola
}

Heloísa Dupas Penteado

Professora do Programa de Pós-graduação da Faculdade de Educação da Universidade de São Paulo - FE/USP.

E-mail: dupaspenteado@hotmail.com

Resumo: $\mathrm{O}$ artigo é resultado da mesa temática O Espaço da Mídia na Escola (2008) e da criação do curso de Licenciatura em Educomunicação, pelo Conselho Universitário da USP (2009). A autora propõe uma reflexão e algumas indagações, situando a necessidade de se compreender que espaços de articulação são necessários para a criação de um profissional com conhecimentos do campo da Comunicação e da Educação em suas dimensões pedagógica e didática, de modo a contribuir com a formação de professores de todos os níveis de ensino e com a qualificação das instituições escolares. A autora destaca, predominantemente, o espaço da Docência no Ensino Básico, em seus três níveis de ensino (EB, EF1e2, EM), e no Ensino Universitário. Com a aprovação pelo Conselho Universitário, em 2009, do Curso de Licenciatura em Comunicação, considera a criação do novo espaço como possível articulador, por excelência, de instituições universitárias como ECA/USP e FE/USP, diretamente relacionadas com a Educação como um processo específico de Comunicação.

Palavras-chave: comunicador educacional, educação, comunicação, Ensino Básico, instituição escolar.
Abstract: This article results from the thematic table The Space of Media in School (2008) and the creation of the undergraduate course of teachers formation in Educommunication, by the University Council of Universidade de São Paulo (2009). The author proposes a reflection and places some issues, setting the need of understanding that spaces of articulation are needed in order to create a professional with expertise in the fields of Communication and Education in its pedagogical and dicdatical dimensions to contribute to the formation of teachers for all levels of education and with the qualification of educational institutions. The author points out, predominantly, the Space of Teaching in Primary Education in its three levels (EB EF1e2, IN), and in the University Education. With the approval by the University Council of the undergraduate course of Teaching of Communication, in 2009, she indicates the creation of this new space as possible articulator, by excellence, of university institutions such as ECA/USP and FE/USP, which are directly connected to Education as a specific process of communication.

Keywords: educational communicator, education, communication, primary education, educational institution.

O fato de dedicar-me a estudos e pesquisas sobre Educação, enquanto um processo de comunicação, e à docência, em curso de Licenciatura (formação de professores) na Faculdade de Educação da Universidade de São Paulo (FE/ USP), valeu-me um gentil convite de alunos da Escola de Comunicação e Artes da Universidade de São Paulo (ECA/USP) para, no dia 12 de novembro de 2008, participar de uma mesa temática, com o encargo de abordar o tema O espaço da mídia na escola.

Recebido: 09.12.2009

Aprovado: 19.03 .2010 
O material que me foi disponibilizado (Projeto de Licenciatura em Educomunicação - ECA, 2006, e Lei Educom, 2004) para refletir junto com todos os presentes colocou-me inicialmente a necessidade de esclarecer alguns conceitos, de onde parto, que me parecem fundamentais para uma boa compreensão do ponto de vista aqui adotado. São eles:

1. Licenciatura: curso de formação inicial de professores do Ensino Básico, nível de ensino que compreende: a Educação Infantil, o Ensino Fundamental 1 ( $1^{\underline{a}}$ a $5^{\mathrm{a}}$ séries), o Ensino Fundamental 2 (6 $6^{\mathrm{a}}$ a $9^{\mathrm{a}}$ séries) e o Ensino Médio (art. 21, Cap. I, LDB 9394/96).

2. Formação de Professores, compreendendo a Formação Inicial e a Formação Continuada, realizada ao longo do exercício do magistério.

3. Educação Escolar: processo específico de comunicação. A especificidade reside no fato de constituir uma relação sociopedagógica dos sujeitos da educação escolar (professores e alunos) com conhecimentos: os elaborados e universalmente reconhecidos (de que os professores são representantes) e os demais conhecimentos presentes na sala de aula, na comunidade escolar e na sociedade inclusiva (de que também são portadores professores e alunos); realiza-se em exercícios de significação e ressignificação, com vistas à qualificação da vida e ao exercício da cidadania. Trata-se de processo intencional e sistematizado ${ }^{1}$.

4. Modelos de Educação Escolar:

a) Modelo Tradicional de Ensino, de caráter Informativo: atribui ao aluno o papel de acatar informações sem questionamentos, reproduzi-las de maneira teórica e individual, preparando-o assim para submissão inquestionável a autoridades, para viver relações de dominação/subordinação, de caráter autoritário, características de sociedades patriarcais de passado colonialista. Atribui ao professor o desempenho de atos de docência, individuais e solitários, ou , quando muito, trocados com seus pares, mas nunca com os alunos².

b) Modelo Renovado de Ensino, de caráter Comunicacional: prevê para alunos e professores uma atuação em parceria. Por meio de experiências de tomadas de decisões conjuntas (entre si e com os professores) e de atividades de estudos e procedimentais, busca desenvolver competências, atitudes, habilidades, valores, essenciais para o aluno viver as relações sociais características de uma sociedade democrática, que tem como suporte imprescindível o desenvolvimento afetivo/cognitivo/crítico, construtivo/colaborativo ${ }^{3}$. A Metodologia Comunicacional de Ensino tem por princípio a auteridade, ou seja, colocar-se no lugar do outro interlocutor, qualquer que seja a sua faixa etária e condição sociocultural. Apoia-se em um conceito de ser humano enquanto ser de comunicação, que se expressa através de linguagens e através delas realiza sua sociabilidade; dotado da capacidade de significação, através da qual produz cultura, características que precisam ser consideradas na construção de relações sociopedagógicas do modelo renovado de ensino. 
A leitura do Projeto de Licenciatura da ECA me conduziu à seguinte indagação: que profissionais pretende formar?

Entendo-o como uma proposta de curso de graduação para a formação de comunicadores compromissados com os efeitos educacionais da comunicação midiática em três modalidades educacionais ali considerados:

1. da educação formal institucionalizada;

2. da educação não formal (tipo ONGs etc);

3. da educação informal, focalizada nas mídias.

Entendo ainda que a formação de professores para disciplina que estou chamando aqui, provisoriamente, de comunicação profissional, para o Ensino Médio profissionalizante (Técnico de Comunicação), pode ser encaminhada de maneira diferente, como considerarei mais adiante.

\section{ESPAÇOS NECESSÁRIOS DA MÍDIA NA ESCOLA}

Da leitura desse projeto, de minha experiência docente no Ensino Básico e na Educação Universitária em nível de graduação e pós-graduação, voltada para a formação de professores para o Ensino Básico, nos quais atuo entrelaçando comunicação escolar com mídias no ensino, e de minha reflexão, estudos e pesquisas sobre essa relação, compreendo três espaços como de articulação necessária:

- Diferentes níveis de ensino (Educação Básica e Educação Universitária);

- Diferentes canais educativos (Educação Formal Institucionalizada, Não Formal e Informal);

- Diferentes instituições universitárias (entre si e com o Ensino Básico).

$\mathrm{Na}$ articulação desses espaços, procedimentos que contemplem a interdisciplinaridade e transdisciplinaridade nos processos educacionais são exigência para uma maior aproximação afetivo-cognitiva da complexidade da realidade $\mathrm{bio} / \mathrm{psico} / \mathrm{social}$ e socioambiental, que caracterizam a vida social e o mundo da escola, para assim melhor contribuir para a qualificação, vale dizer, humanização da vida através da educação escolar.

Considero aqui quatro espaços institucionais escolares, promissores dessa articulação necessária, a saber:

1. o espaço da docência no Ensino Básico;

2. o espaço da formação inicial de professores (licenciatura), na Universidade, modalidade presencial e a distância;

3. o espaço da formação continuada de professores em exercício nos diferentes níveis do Ensino Básico, nas modalidades presencial e a distância. A formação continuada atendendo à necessidade de constante atualização profissional em face do acelerado ritmo de produção de conhecimento da sociedade contemporânea, resultante mesmo dos avanços das mídias tecnológicas;

4. o espaço de formação de profissionais de diferentes áreas de conhecimento e de diferentes setores de trabalho. 
comunicação \& educação • Ano XV • número 2 • maio/ago 2010

Vou me deter aqui, predominantemente, no espaço da docência no Ensino Básico em seus três níveis de ensino (EB, EFle2, EM) e no Ensino Universitário, em que essa articulação pode, necessita e deve ser realizada.

\section{O ESPAÇO DA DOCÊNCIA NO ENSINO BÁSICO}

O espaço da docência realiza-se em três diferentes níveis de ensino, com suas especificidades.

\section{Educação Infantil}

No espaço da Educação Infantil a presença das mídias no universo cultural das crianças é uma evidência: nas brincadeiras, nos gestos, nas conversas entre elas, em suas expressões verbais, nas reivindicações e hábitos alimentares, nos seus desejos e sonhos, na identificação com brinquedos e brincadeiras repetidamente apresentados a elas por uma TV comercial (ainda que não só por ela), compromissada com o consumismo gerador de lucros das empresas que a financia.

Embora a extensão desse traço cultural na vida das crianças seja constatada pelos professores, e até mesmo admitida a necessidade de um ensino com mídias na escola, este forte traço cultural da vida dos pequenos, de modo geral, é ignorado no trabalho pedagógico neste nível de ensino, ainda que alguns comportamentos negativos ou inadequados a situações de ensino escolar desenvolvidos pelas crianças sejam constatados e atribuídos especialmente à mídia TV pelos professores.

Estudos e pesquisas recentes da Sociologia da Infância chamam a atenção para a vida social da criança, como nos adverte Pontes, citando Corsaro: "As crianças são agentes ativos, que constroem suas próprias culturas e contribuem para a produção do mundo adulto"s. E, nesta condição, não se limitam à incorporação da cultura do mundo adulto "mas são capazes de construir seus processos de apropriação, reinvenção e reprodução"

Citando Delgado e Muller, Pontes esclarece que:

4. CORSARO, William (1997), apud PONTES, Aldo N. A educação das infâncias na sociedade midiática: desafios para a formação de professores.

(Tese) Faculdade de Educação da Universidade de São Paulo - USP, São Paulo, 2010. p. 38.

5. Ibid.

6. DELGADO, Ana Cristina Coel; MULLER, Fernanda (2005), apud PONTES, op. cit., p. 38-39.
[...] a sociologia da infância estimula compreensão das crianças como atores capazes de criar e modificar culturas, embora inseridas no mundo adulto. Se as crianças interagem no mundo adulto porque negociam, compartilham e criam culturas, necessitamos pensar em metodologias que realmente tenham como foco suas vozes, olhares, experiências e pontos de vista ${ }^{6}$.

Tal concepção implica, na Educação Infantil, a necessidade de uma leitura pelo docente da relação criança/mídias, especialmente TV, bem como da apropriação e do aproveitamento que podem fazer dessa leitura em seu ensino - em rodas de conversa e em brincadeiras orientadas e jogos -, que possibilitem a ampliação de significações já construídas pelas crianças a partir dos conteúdos das mídias tecnológicas presentes em seu universo cultural, promovendo 
ressignificações possíveis de serem construídas com base nessa experiência midiática, articulando-a com as demais experiências de vida infantil. Cabe ao professor, como mídia humana que é ${ }^{7}$, propiciar aos pequenos, em vivências escolares, essa articulação entre as duas experiências infantis, midiática e de vida, propiciadoras e ampliadoras de novas possibilidades de compreensão das duas experiências.

A esse respeito a dissertação de mestrado de Márcia Barbosa da Silva ${ }^{8}$ e a pesquisa de doutorado de Aldo Pontes ${ }^{9}$ são trabalhos ilustrativos de possibilidades da metodologia comunicacional de ensino com mídias nesse nível de ensino. Em outras palavras, a concepção de criança, aqui adotada, implica preparar professores para o trabalho com mídias na escola e para conhecer os seus alunos para além das aparências, o que exige o aprendizado de uma docência investigativa e, portanto, comunicaional, realizada por procedimentos de pesquisa-ensino, uma modalidade de pesquisa-ação ${ }^{10}$.

De outro lado, temos uma escola que vem mantendo em todos os níveis de ensino relações meramente burocráticas e não educativas com pais e familiares que, premidos pelas exigências de trabalho para garantir a sobrevivência da família, entregam seus filhos à babá eletrônica, única forma encontrada para prevenir a segurança de seus filhos, fechando-os dentro de casa, com pleno acesso à TV.

Chamados à escola apenas para reuniões bimestrais, ou para serem informados dos rendimentos ou de situações problemáticas das crianças, a escola deixa de reconhecer a família como coadjuvante importante da educação escolar dos filhos, qualquer que seja o seu nível cultural, especialmente no que se refere à exposição da criança à TV e internet, mantendo com os pais e/ou responsáveis relações desgastantes.

É preciso reconhecer esse papel da família e para o qual precisa ser despertada, alertada, preparada, educada mesmo pela escola, para intensificação de vínculos construtivos entre as duas instituições educadoras, tendo em vista um melhor aproveitamento escolar de seus filhos.

Apenas um processo de comunicação escola-família - diferentemente do processo informativo burocrático atual - voltado para a construção de vínculos construtivos, que articulem entre si suas ações educativas, possibilitará construir essa parceria.

Neste sentido, a pesquisa-intervenção de Borsato ${ }^{11}$ investiga a relação escola-família em uma escola pública de Ribeirão Preto (SP) que atende alunos com defasagem escolar, procedentes de bairro carente da cidade. Por meio de uma abordagem psicodramática, trabalhando com grupos de professores e pais, separadamente e em conjunto, evidencia a possibilidade e o potencial de um processo comunicacional com essa metodologia. Conscientiza professores e pais do afastamento constatado entre escola e família, promove a aproximação entre ambas e esclarece possibilidades de qualificação do universo cultural das crianças, que pode ser alcançada por atuações decorrentes de uma comunicação em sintonia entre as duas instituições, como esta a que a referida pesquisa deu início.
7. PENTEADO, op. cit.

8. SILVA, Márcia B. A criança e a televisão: que contribuições ao trabalho docente na pré-escola. Dissertação (Mestrado). Departamento de Metodologia do Ensino e Educação Comparada, Faculdade de Educação da Universidade de São Paulo - FE/USP, 1997.

9. PONTES, op. cit.

10. PENTEADO, Heloísa D. Pesquisa-ensino: uma modalidade de pesquisa-ação. Cadernos de Pesquisa em Educação, Vitória: PPGE-UFES, v. 14 , n. 28 , p. 102-121, jul./ dez. 2008b.

11. BORSATO, Cláudia R. Relação escola e família: uma abordagem psicodramática. Tese (Doutorado). Departamento de Metodologia do Ensino, Faculdade de Educação Comparada, Universidade de São Paulo - FE/ USP, 2008. 
12. PROGRAMA de Educomunicação Socioambiental. Brasília: Ministério do Meio Ambiente, 2005. p. 12.

13. VIANA, Claudemir. O lúdico e a aprendizagem na cibercultura: jogos digitais e internet no cotidiano infantil. Tese (Doutorado). Escola de Comunicações e Artes, Universidade de São Paulo - ECA-USP, 2005. $275 \mathrm{p}$.

14. Ibid., p. 224.
Nas circunstâncias atuais, anteriormente consideradas, espaços para trabalho pedagógico com mídias na escola se delineiam como necessidades presentes e prementes nas escolas de Educação Infantil, em processos de formação contínua de professores, capacitante para o trabalho docente sobre a relação crianças/mídias. O que exige um serviço de apoio a professores em exercício, e que não foram preparados para tanto em sua formação inicial, a ser realizado pelo profissional comunicador compromissado com os processos educacionais escolares, ou seja, por profissionais formados pelo chamado Projeto de Licenciatura da ECA. O que também abre espaço para se pensar em uma equipe de plantão, de comunicadores educacionais, dentro da própria ECA (e até mesmo a ser considerado dentro do curso proposto pelo projeto), de pronto atendimento à solicitação de professores em exercício e de acompanhamento de seus trabalhos com mídias junto aos pequenos.

De onde também se conclui a correspondente exigência de que os cursos iniciais de formação de professores introduzam necessariamente os professorandos aos ecossistemas comunicativos com o objetivo de ampliar formas de expressão e melhoria do coeficente comunicativo das ações educativas... para o pleno exercício da cidadania, conforme prevê o Programa de Educomunicação Socioambiental ${ }^{12}$, introdução essa que supõe a presença do comunicador educacional como formador de professores

\section{Ensino Fundamental I (séries iniciais)}

Nas séries iniciais ( $1^{\mathrm{a}}$ a $5^{\mathrm{a}}$ séries) do Ensino Fundamental, a presença das mídias continua uma evidência na cultura infantil. $\mathrm{O}$ avanço no desenvolvimento bio/psico/social dos alunos permite dar continuidade às experiências com mídias na escola, em vivências de leituras que desenvolvam relações indagativas/ criativas/crianças/mídias. Ouvir as crianças sobre um programa, um comercial, filme ou desenho a que costumam assistir, ou sobre jogos digitais com que estão habituados; promover a exibição de algum deles em classe, problematizar cenas e propiciar comentários, provocando o relacionamento do que se viu e do que se vê no contexto de suas vidas; e ampliar os significados com proposições de dramatizações em que ocorram variações sobre o mesmo tema, são algumas formas de desenvolvimento da imaginação criadora a partir da leitura das mídias e de criação de espaços de indagação e de reelaboração das crianças.

Em sua tese de doutorado ${ }^{13}$, Claudemir Viana, componente da equipe de uma escola particular de São Paulo, analisa a relação de crianças entre 8 e 10 anos com jogos digitais na internet. Chama a atenção em seu estudo para o fato de as crianças ressignificarem os conteúdos presentes no seu ambiente, o que revela esses jogos como "excelente dispositivo para interagir com o ambiente em que vive, com suas coisas, fatos, sentimentos, pessoas, por meio dos símbolos e metáforas presentes nas narrativas dos produtos com suporte midiático" ${ }^{14}$. As atividades relatadas no trabalho oferecem dados para a construção do que eu chamo exercícios-brincadeiras, nos quais problematizar algumas das situações leva 
O espaço da mídia na escola - Heloísa Dupas Penteado

as crianças a vivenciarem experiências de leitura de mídias que as exercitam para uma relação indagativa com os jogos de internet. Constata o referido autor que meninas gostam muito de brincar com jogos da boneca Barbie na internet. $\mathrm{O}$ gosto é despertado e mantido pela oportunidade de participação, que na verdade é administrada pelo jogo. Todavia, utilizando o próprio jogo é possível criar um espaço de liberdade nessa participação da criança, com provocações didáticas do professor. Por exemplo, em relação à tela em que Barbie se encontra diante de inúmeras alternativas de pares de sapatos, depois de explorarem algumas alternativas do jogo, é possível pensarmos em provocar as crianças com questões do tipo:

- Quantos pares de sapatos tem a Barbie?

- E você, quantos pares tem? Alguém tem mais do que isso? Alguém tem menos?

- Será que a gente precisa de tantos pares de sapato assim?

- Será que a Barbie sabe andar descalça?

- Alguém daqui já andou descalço?

- O que percebemos quando andamos descalços? E o que não percebemos?

- Por que devemos andar calçados?

- $\mathrm{O}$ que pode acontecer com a Barbie andando com sapatos tão altos?

Ou seja, é possível fazer as crianças articularem jogo e ambiente em que vivem, a considerar outros valores como, nesse caso, a saúde, o conforto dos pés, levando-as para além do estímulo ao consumo implícito no jogo. Basta para tanto acolher as respostas as mais diversas que poderão surgir, provocar comentários e considerações sobre elas. Lembramos aqui as propriedades do psicodrama socioeducativo para a realização desses exercícios, uma vez que tal metodologia propicia participação efetiva das crianças com o tema considerado, inter-relação entre elas em situação de jogo, muito adequada aos interesses da faixa etária.

\section{Ensino Fundamental II (5a a $9^{\text {a }}$ séries)}

Nas séries mais avançadas do Ensino Fundamental (6 $6^{\underline{a}}$ a $\left.9^{\underline{a}}\right)$ é desejável e necessário acrescentar à recepção indagativa/criativa a ampliação de formas de expressão dos alunos, com a introdução ao uso criativo de diferentes linguagens, além da oral e escrita. É desejável pelo gosto e interesse que os jovens adolescentes demonstram pelas mídias, portadoras e/ou sintetizadoras de diferentes linguagens; e necessário pelo papel ocupado pelas diferentes linguagens midiáticas constituintes de processos de comunicação, pelos quais se realizam as relações humanas nos mais diferente setores da vida social contemporânea, aparentemente de maneira neutra e desinteressada. Desvelá-las em suas intenções implícitas, desdobrá-las em descobertas de outros valores a elas relacionados, além dos nelas dissimulados, elaborar novas mensagens em que o potencial dos signos das diferentes linguagens possam ser utilizados de maneira a potencializar sentidos construtivos, é iniciar a compreensão da articulação 
comunicação \& educação • Ano XV • número 2 • maio/ago 2010

das diferentes linguagens midiáticas (especialmente da TV com valores e de conteúdos das diferentes áreas de conhecimento). O que não só é possível, a partir de jogos também lúdicos postos pelos professores, que estimulem e ampliem as relações possíveis de serem estabelecidas pelos pré-adolescentes e adolescentes com o seu cotidiano, como se torna indispensável na formação de cidadãos esclarecidos e participativos, exigidos pelas sociedades tecnológicas da contemporaneidade.

No livro A atividade de ensino de História: processo de formação de professores e alunos $^{15}$, Olavo Pereira Soares, meu ex-orientando, relata experiências suas de docência na disciplina História, com mídias, no EF II e no EM, que ilustram com muita clareza a propriedade dessa modalidade de ensino, seja pelo interesse despertado, seja pelos resultados alcançados.

Evidencia-se que tal ensino exige professores pedagogicamente capacitados para o ensino com mídias na escola, o que nos remete a espaços formadores anteriormente considerados, quais sejam: formação continuada de professores em exercício nas escolas em que atuam, a ser monitorada por comunicadores educacionais; plantões desses profissionais na ECA, onde os professores possam encontrar apoios para a elaboração e realização de seus projetos de ensino com mídias; cursos iniciais de formação de professores das diferentes áreas de ensino que contem com comunicadores educacionais como formadores, para capacitar professorandos na leitura, na expressão e no uso pedagógico de diferentes linguagens de diferentes mídias, no trabalho docente com elas, didaticamente fundamentado.

\section{Ensino Médio}

No EM, seja em sua modalidade propedêutica, que encaminha o estudante para profissões de nível universitário, seja na modalidade profissionalizante, para profissões de nível técnico, o desenvolvimento de capacidades comunicacionais, ampliadas pelo conhecimento de potencialidades de diferentes linguagens utilizadas por diferentes mídias tecnológicas em diferentes espaços profissionais, precisa necessariamente ser garantida.

No Ensino Médio Propedêutico, a ampliação de tais capacidades vai ganhando maiores possibilidades em decorrência do nível de desenvolvimento biopsicossocial dos discentes, promotor de maior amadurecimento. Penso mesmo na possibilidade de criação de disciplina - Linguagens das mídias: leitura e produção de textos e valores -, ministrada por comunicadores educacionais com habilitação docente, ou mesmo de um espaço escolar, tipo um laboratório de mídias monitorado por um comunicador educacional, com habilitação docente atuando em conjunto com professores das diferentes áreas do conhecimento e seus alunos, para o aprofundamento de leitura crítica e para a produção de textos

15. SOARES, Olavo P. A atividade de ensino de História: processo de formação de professores e alunos. Araraquara, SP: Junqueira\&Marin, 2008. midiáticos não só comprometidos com efeitos especiais, ou seja, com a técnica, mas, principalmente, com valores construtivos e simultaneamente envolventes e convincentes. 
Encontramos relato de uma docência nessa direção, no livro já anteriormente citado de Olavo Pereira Soares. Pesquisando sua própria docência, o autor atua na interface cultura escolar e cultura das mídias de que os jovens são portadores nesse nível de ensino, servindo-se de textos de linguagens diversas, além da escrita, como musical, pictórica, cinematográfica, para estimular e desenvolver ressignificações de experiências de vida dos alunos a partir da articulação entre seus contextos de vida e seus tempos, com os valores embutidos nos textos midiáticos e seus diversos tempos. Ressalta o referido autor a habilidade de professor-pesquisador ${ }^{16}$, que teve em seu curso de formação inicial de professores, como indispensável para a realização de tais procedimentos.

No EM, em sua modalidade profissionalizante, a importância da ampliação da capacidade de expressão em diferentes linguagens é evidente nas sociedades tecnológicas, pelas exigências postas por um mercado de trabalho desdobrado em múltiplas profissões que se detêm em competências técnicas.

No EM Técnico Profissionalizante, voltado para a formação do Técnico em Comunicação, é necessário caminhar de uma compreensão ética do exercício da profissão, através de observações do trabalho de diferentes profissionais da área de comunicação, e de uma experiência ética vivenciada em estágios para uma ética refletida que lhe possibilite construir o seu referencial de valores profissionais, que o encaminhe para muito além da competência técnica; ou seja, que lhe permita alcançar a amplitude da dimensão socioeducativa de seu trabalho, como parâmetros para a adesão consciente a projetos, em que a atuação técnica, que não é neutra, seja compromissada com valores construtivos.

Para tanto, neste nível de ensino penso mesmo ser indispensável a criação de disciplina tipo comunicação, linguagens das mídias e valores, com iniciação teórica e iniciação prática, ministrada por comunicador educacional e com suporte de laboratórios e oficinas de informática, para a formação de técnicos compromissados com os efeitos educacionais de sua atuação profissional.

\section{O ESPAÇO DA FORMAÇÃO DE PROFESSORES}

O espaço da Formação de Professores compreende duas modalidades:

1. A Formação Inicial realizada nos cursos de Licenciatura da Faculdade de Educação, destinada à demanda de graduandos dos diferentes Institutos da Universidade de São Paulo, que desejam habilitar-se para a docência em áreas correspondentes à sua graduação, existentes no Ensino Básico;

2. A Formação Contínua de Professores, ao longo do exercício do magistério.

Em pesquisas realizadas com professores de diferentes níveis de ensino, depoimentos revelam a falta de formação inicial para o trabalho com mídias na escola, a pouca percepção que têm do interesse em mídias de crianças e jovens, bem como das influências do consumo midiático em comportamentos e aprendizagens dos alunos. Tal situação aponta para a urgente necessidade
16. Professor pesquisador: professor do EB que faz de sua docência um ato simultâneo de pesquisa. 
comunicação \& educação • Ano XV • número 2 • maio/ago 2010

17. BERGMANN, Helenice M. Escola e inclusão digital: desafio na formação de redes de saberes e fazeres. Tese (Doutorado). Departamento de Metodologia do Ensino Faculdade de Educação Comparada, Universidade de São Paulo - FE/USP, 2006.

18. Pesquisa-ensino: modalidade de pesquisa-ação realizada enquanto ato de docência pelo professor-pesquisador (a respeito, no prelo, o livro Pesquisa-ensino: a comunicação escolar na formação do professor, de H. D. Penteado e E. Garrido, organizadores). de introdução nas licenciaturas, para a formação de professores das diferentes áreas de conhecimento componentes do Ensino Básico, de uma disciplina teórico/prática sobre Linguagem das mídias, ministrada por comunicadores educacionais que capacitem os professorandos a utilizá-las em suas práticas docentes (além e/ou conjuntamente com a linguagem escrita, como até já requer a internet), ampliando as formas de expressão docente, de tal forma a propiciar diferentes possibilidades de compreensão dos alunos, tão afeitos aos textos da mídia eletrônica na atualidade. Todavia, entendo que tal formação deva ser ministrada por um comunicador educacional em conjunto com um professor de Prática de Ensino (de História, de Geografia, de Matemática etc), para assim poder atender às especificidades didáticas requeridas em cada área de conhecimento, ou seja, às anteriormente chamadas Didáticas Especiais, hoje realizadas nas disciplinas de Prática de Ensino das diferentes áreas, ministradas por especialistas desses diferentes campos. O trabalho conjugado de ambos certamente resultará em enriquecimentos recíprocos. Uma leitura que pode ser elucidativa sobre inclusão digital de professores em exercício encontra-se em Escola e inclusão digital: desafios na formação de redes de saberes e fazeres, de Helenice M. Bergmann ${ }^{17}$.

\section{FORMAÇÃO DE PROFISSIONAIS DE DIFERENTES ÁREAS DO CONHECIMENTO E DE TRABALHADORES DE DIFERENTES SETORES}

Muitas das dificuldades vividas em áreas diversas de setores de trabalho, como Saúde, Engenharia, Administração, dentre outros, são decorrentes de problemas de comunicação entre os agentes sociais envolvidos, muitos deles procedentes de segmentos socioculturais diversos e distantes entre si, em que a linguagem falada e escrita de tais profissionais não é compreensível a seus interlocutores-alvo no exercício da profissão. Assim, dotar esses profissionais de conhecimentos midiáticos, de tal forma a poderem servir-se de diferentes mídias e de suas linguagens na comunicação profissional como forma de expressão, é recurso capacitante para o bom êxito profissional.

\section{SINTETIZANDO}

Entendo que uma proposta de formação do Comunicador Educacional deve ocorrer na interface institucional entre Escola de Comunicações e Artes e Faculdade de Educação, ECA-FE/USP, para dar conta de uma formação interinstitucional/interdisciplinar capaz de abranger as múltiplas e diferenciadas exigências de docências em espaços escolares múltiplos e tão diversificados como os anteriormente considerados.

Venho trabalhando com a metodologia de Pesquisa-ensino ${ }^{18}$, uma modalidade de Pesquisa-ação que se realiza em procedimentos de docência compartilhada 
e colaborativa, que providencia trocas significativas de conhecimentos entre os participantes, podendo encaminhar férteis descobertas para os respectivos campos de conhecimento, decorrentes de ação conjunta; comunicação e educação, no caso aqui considerado. Deixo aqui o meu desejo/esperança dessa importante parceria e o meu agradecimento pelo convite para participação nesta mesa.

\section{REFERÊNCIAS BIBLIOGRÁFICAS}

BERGMANN, Helenice M. Escola e inclusão digital: desafio na formação de redes de saberes e fazeres. Tese (Doutorado). Departamento de Metodologia do Ensino, Faculdade de Educação Comparada, Universidade de São Paulo - FE/USP, 2006.

BORSATO, Cláudia R. Relação escola e família: uma abordagem psicodramática. Tese (Doutorado). Departamento de Metodologia do Ensino, Faculdade de Educação Comparada, Universidade de São Paulo - FE/USP, 2008.

CORSARO, William A. The sociology of childhood (A sociologia da infância). Califórnia: Pine Forge, 1997.

DELGADO, Ana Cristina Coel; MULLER, Fernanda. Sociologia da infância: pesquisas com crianças, v. 16, n. 91, maio/ago. 2005.

PENTEADO, Heloísa D. A mídia humana e outras mídias. In: PONTES, Altem; PONTES, Aldo N. (Org.). Pesquisa e prática docente sobre educação e comunicação. Belém: UEPA Ed., 2008a.

. Pesquisa-ensino: uma modalidade de pesquisa-ação. Cadernos de Pesquisa em Educação, Vitória: PPGE-UFES, v. 14, n. 28, p. 102-121, jul./dez. 2008b.

Psicodrama, televisão e formação de professores. Araraquara (SP): Junqueira\&Marin, 2007.

Comunicação escolar: uma metodologia de ensino. São Paulo: Salesiana, 2002.

; GARRIDO, E. (Org.). Pesquisa-ensino: a comunicação escolar na formação do professor. No prelo.

PONTES, Aldo N. A educação das infâncias na sociedade midiática: desafios para a formação de professores. (Tese) Faculdade de Educação da Universidade de São Paulo - USP, São Paulo, 2010.

PROGRAMA de Educomunicação Socioambiental. Brasília: Ministério do Meio Ambiente, 2005. p. 12.

SILVA, Márcia B. A criança e a televisão: que contribuições ao trabalho docente na pré-escola. Dissertação (Mestrado). Departamento de Metodologia do Ensino e Educação Comparada, Faculdade de Educação da Universidade de São Paulo - FE/USP, 1997. 
comunicação \& educação • Ano XV • número 2 • maio/ago 2010

SOARES, Olavo P. A atividade de ensino de História: processo de formação de professores e alunos. Araraquara, SP: Junqueira\&Marin, 2008.

VIANA, Claudemir. O lúdico e a aprendizagem na cibercultura: jogos digitais e internet no cotidiano infantil. Tese (Doutorado). Escola de Comunicações e Artes, Universidade de São Paulo - ECA/USP, 2005. 275 p. 